\title{
Food Insecurity and its Effect on Mental Health: A Systematic Review
}

\author{
${ }^{1}$ Hamna Zahid, ${ }^{1}$ Sana Noreen, ${ }^{1}$ Bahisht Rizwan, ${ }^{2}$ Shahid Bashir, ${ }^{1}$ Shahwar Javaid, \\ ${ }^{1}$ Mujeeb Ur Rehman, ${ }^{1}$ Dua Waqar, ${ }^{1}$ Ayza Hashmi, ${ }^{1}$ Mahnoor Khalid, ${ }^{1}$ Kinza Kashif, ${ }^{1}$ Osama Rasheed \\ ${ }^{1}$ University Institute of Diet and Nutritional Sciences, The University of Lahore, Lahore \\ ${ }^{2}$ University Institute of Food Sciences and Technology, The University of Lahore, Lahore
}

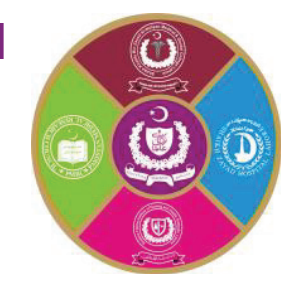

\begin{abstract}
Introduction: Food security is a rising concern worldwide. It is estimated that more than one billion people lack adequate supply of dietary energy and that at least half that amount suffers from micronutrient deficiencies. It is influenced by several factors: income, employment, race/ethnicity and disability, which adversely affect health. Food security has been considered as a risk factor for depression, stress and anxiety.

Aims \& Objectives: The research aimed to find the effect of food insecurity on mental health using systematic analysis. Place and duration of study: Data was gathered using Google Scholar, Medline, Embase, Science Direct and books from studies conducted between 2015 and 2020.

Material \& Methods: Systematic analysis was conducted with references to the literature.

Results: This review showed a strong link of food insecurity with mental health status like depression, anxiety, and stress.

Conclusion: Based on the results of this study, the tests of depression and mental health in both secured and foodinsecure food areas should be mandatory at the primary health level. It is suggested that food insecurity interventions on national and regional levels may help reduce the prevalence of depression, anxiety, and stress and improve the overall mental health status of the community.
\end{abstract}

Key words: Food Insecurity, Mental Health, Malnutrition, Low Income, Depression, and Anxiety

\section{INTRODUCTION}

F ood security is defined as the secure ability to receive adequate and nutritious food to meet requirements in addition to find a socially acceptable way. ${ }^{1}$ On the other hand, "food insecurity is a result of scarce resources which impacts many households across the world, leading to malnutrition". ${ }^{2}$ Food security refers to everyone having adequate food to live a healthy, productive life. Households that are food-safe will reliably achieve sufficient nutrition. On the other hand, families that have food insecurity are often not able to provide sufficient food for family members because they lack resources and other food related services. ${ }^{3}$ Food security is vital to the health of every nation and stresses the need to pay attention to food security at global, provincial, household and individual levels. This is important to preserve political order, control increasing demographic pressure, eradicate hunger and prevent violence and instability. Various reports produced by the World Food Programme (WFP) illustrate the significance and status of food insecurity around the world. Food insecurity is generally explained as "lack of access to an adequate quantity of affordable and nutritious food". It is a social and economic condition with implications of whole life. Risk factors for assured mental illness are strongly associated with uncomplimentary social conditions. ${ }^{4}$ Mental disorders are very common in people suffering food poverty; also, mental illnesses and food insecurity co-occur overwhelmingly in more females as compared to males. ${ }^{5}$

In the world, where 925 million people are undernourished, food insecurity is mounting. Approximately 900 million people live in developing countries, and over $70 \%$ live in rural areas, depending directly or indirectly on agriculture for their livelihoods. Because of the lack of nutritious access to food, 33 percent of young children are still counted as underweight, according to the National Nutrition Survey. In 2005, it was noted that 54 percent of children living in developing countries died from malnutrition. In those countries that show an average or above $15 \%$ malnutrition among residents, the WHO identifies the emergency. For the health of every country, food security is crucial. ${ }^{4}$ It is well recognized that on 
many socio-economic and political fronts, Pakistan is a developing nation. Pakistan has been classified as a high-risk country for food insecurity in the 2019 Global Food Security Index (GFSI). Various South Asian reports suggest that South Asian governments are doing their hardest to ensure food security and to get rid of poverty and malnutrition.

Recent studies suggested that $68 \%$ population of Pakistan cannot have enough money to buy a staple modified dietary diet. ${ }^{6}$ Food insecurity affects the mental health status of the population. The prevalence of depression in Pakistan is 33 percent, according to a survey focused on 20 studies conducted in the country, with women having a higher prevalence than men. Other studies have concentrated on a few basic psychiatric illnesses like depression and anxiety. ${ }^{7}$ Floods and earthquakes also played a role in mental health in previous years as they made food seriously insecure for the region. A research found that after 2.5 years of flooding in Pakistan, the prevalence of major depressive disorder was 26.8 percent. $^{8}$ Data on mental health issues in Pakistan is very small and needs further study in this area, and the impact of food insecurity on mental health in Pakistan has not been placed into much focus, and hence the literature is missing. Mental health issues refer to "a well-being condition in which the person knows his or her capacity, can cope with life's usual pressures, can work productively and fruitfully, and contribute to his or her society". In addition, behavioral illnesses greatly lead to health care costs and inefficiency. ${ }^{9}$

For a prolonged period of time, a deficiency of macronutrients and micro-nutrients is correlated with effects on learning and behavior issues. Depression and anxiety, with major clinical and economic effects, are the primary causes of morbidity. ${ }^{10}$ Many comorbid disorders, such as lung disease, obesity and diabetes, are also associated with it. Sleep disturbances are also closely correlated with stress and anxiety, contributing to considerable morbidity over time. ${ }^{11}$ Within a group, human nature have many similarities towards sensitivity, and likelihood of taking mental health for granted can contribute considerably to mental health issues. ${ }^{12}$ For those with chronic illnesses, the requirement for routine checkups and daily treatment is a must to improve both physical and mental wellbeing. ${ }^{13}$

\section{MATERIAL AND METHODS}

The present review was undertaken between September 2020 to March 2021. Institutional Review Board Letter Number was received vide UIDNS/2021/5075. In Systematic Reviews conformed to the PRISMA (Preferred Reporting items for Systematic Reviews and Meta-Analyses) declaration criteria. The full set of concerns on food shortage problems and their effect on body health were also reviewed.

\section{Search strategy and study selection:}

To accomplish this goal, Medline, Embase, Science Direct, and Google Scholar were used to search for and review papers written the last five years. Books published on food insecurity and its effects on mental health were studied. Data on the test date, study design, and the main outcome of food insecurity were collected. Non-reproducible studies were discarded while the chosen studies were summarized. The collected details were presented in Table-1.

Inclusion criteria: The articles considered, were describing the relation of mental health like depression, anxiety, and stress with food insecurity or food security in specific age groups and both genders. This study also focused on the risk factors of food insecurity.

Exclusion criteria: This study focused on the link between underdeveloped countries and food insecurity issues, and so data from the developed countries was excluded from this study. People with high incomes were also not included in this study. Conditions like obesity, diabetes, and hypertension were also not considered in this study.

Data Collection: The following details were derived from each study: "author, year of publication; study design; the total number of assessed participants; their risk factors of mental health, and causes of food insecurity".

Data Extraction and Analysis: The study yielded data on the systematic review query items, which were assembled into qualitative tables. As different sample methods include an overview, a specific analysis of food insecurity and its association with mental health was considered.

Study Selection Process: Hundred studies retrieved, " 20 were excluded as duplicated, 65 were excluded as having no access to the full text. Five papers were also omitted if their study topic was irrelevant or did not report any relevant information". 11 articles were selected for recent data selection. 


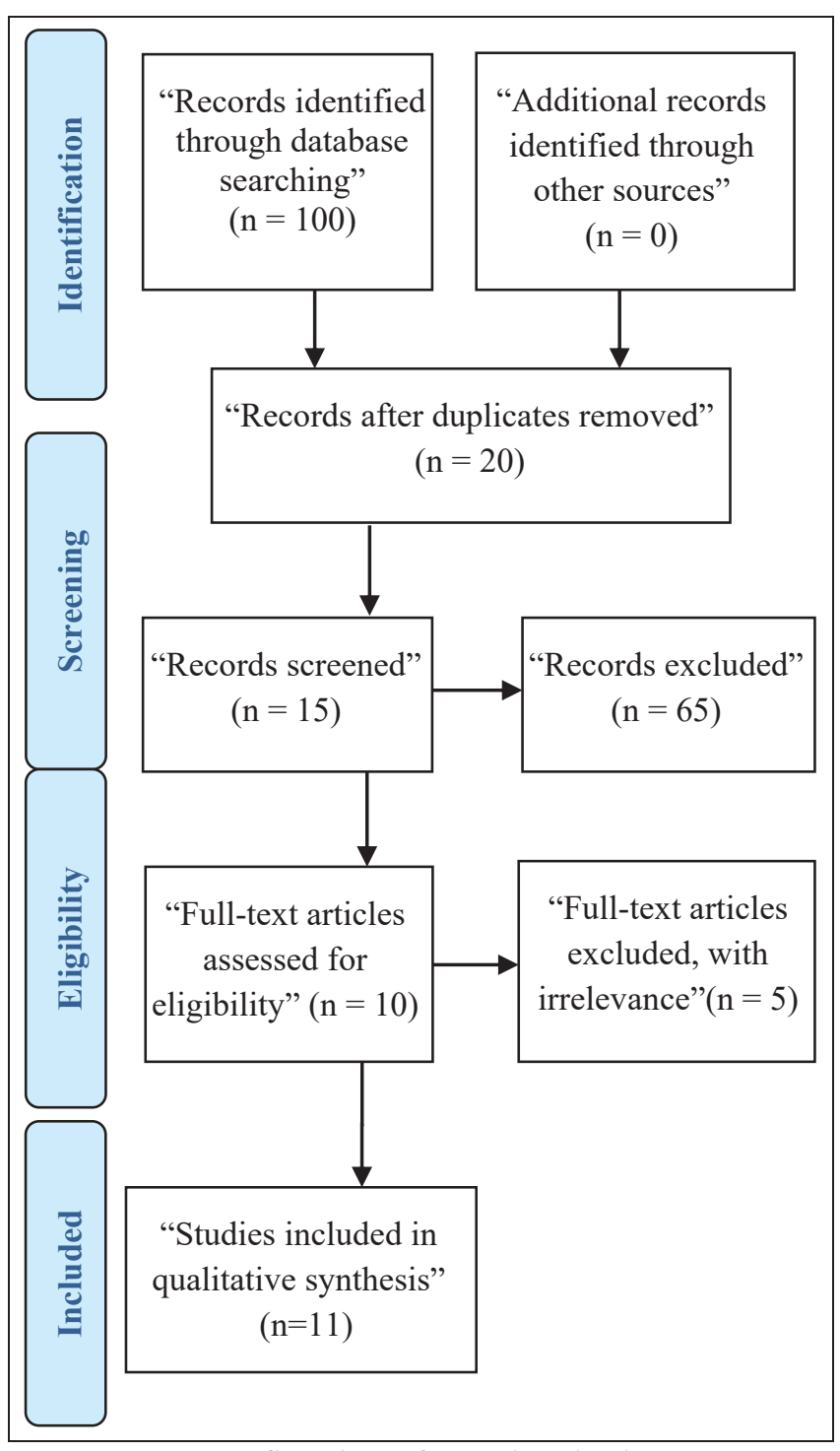

Fig-1: PRISMA flowcharts for study selection

(Results shown in Table)

\section{DISCUSSION}

More than 1 billion people have been reported to insufficient food access because of many reasons, including inadequate financial services and transportation. Food insecurity has gained growing attention worldwide. Depression in turn can also change one's view of food insecurity, and is likely to influence reactions to food insecurity concerns. ${ }^{24}$

Food insecurity is an independent indicator of behavioral, emotional and academic effects because irritability and emotional changes are triggered even temporarily without food, which in turn affect the psychosocial habits of children. However, it has been identified that experiences such as homelessness can be related to another likelihood of food insufficiency. ${ }^{25}$ Food-insecure parents aim to maintain the health of their kids and can deprive themselves of food to encourage kids to eat; parental nutritional deficiency, persistent attempts to maintain the health of their kids may trigger parental distress and irritability, which can impact kids in turn. $^{26}$ In accordance with a previous study, depression and stress revealed a correlation between food deficiency and symptoms of common psychiatric illnesses. ${ }^{27}$

Although the exact mechanisms connecting food insecurity and mild cognitive impairment remain unclear, several theories have been proposed. It's likely that food insecurity related stress heightens the risk of mild cognitive impairment. ${ }^{28}$ Anxiety induced pro-inflammatory cytokines ${ }^{29}$ have also been linked to an increased risk of dementia. ${ }^{30}$ In addition, during shortage of food people tend to consume less nutritious food ${ }^{31}$ which may lead to dementia as they have deficient in micronutrients. ${ }^{32}$ Depression and perceived stress have been strongly related to short as well as long term to food poverty. It was concluded that there is a detrimental association between food poverty and the consequences of childhood behavioral development, including early cognitive growth, academic success, attention span, activity externalization, and depression. Students who did not have enough funds to bear the expenses of their studies were also found to consume micronutrient deficient food and are more exposed to mental health issues. ${ }^{28}$ This research, therefore, found that in developed countries hunger is one of the main causes of food insecurity. Depression and perceived tension are closely related to short-term and long-term food insecurity.

The signs and effects of the mental wellbeing of both genders were found to vary. The poor nutritional condition and the mental health of young people are significantly related to each other. There were discrepancies between genders. For males, fruit and vegetables and food insecurity were important forecasters of depression, and the inclusion of sugar intakes and food insecurity were both significant predictors of anxiety. These findings are linked with previous researches and found variations in dietary patterns of males and females with mental illnesses. ${ }^{33}$ Each indicator of food insecurity was statistically related to more severe psychological distress. Those who reported a lack of food due to financial stress report low to high levels of distress. People utilizing foods having less core nutrition than the average showed more anxiety and the same is the case with people utilizing disposable food. ${ }^{34}$ Malnutrition affects the size and function of the brain. Nevertheless, the effect of food deficiency on brain growth is less well known without significant anthropometric or 
biochemical defects. Recent research has shown that the toxic stimulus in food insecurity has negative effects on brain architecture, according to Cook et al. but no research has been done to validate or reverse this hypothesis. ${ }^{26}$

\section{RESULTS}

\begin{tabular}{|c|c|c|c|c|}
\hline \begin{tabular}{|l|} 
Author \\
\& year
\end{tabular} & \begin{tabular}{|l|}
$\begin{array}{c}\text { Sample } \\
\text { size(n) }\end{array}$ \\
\end{tabular} & $\begin{array}{c}\text { Study } \\
\text { designs }\end{array}$ & Risk factors & Outcomes/Findings \\
\hline \begin{tabular}{l|} 
Arenas \\
et al., \\
2019
\end{tabular} & $\begin{array}{r}169,433 \\
91,957 \\
85,788\end{array}$ & $\begin{array}{l}\text { Cross- } \\
\text { sectional } \\
\text { study }\end{array}$ & Food insecurity & $\begin{array}{l}\text { "An evidence on the relationship between food insecurity and depression ( } \mathrm{n}=169,433) \text {, } \\
13 \text { on anxiety and psychological distress }(\mathrm{n}=91,957), 8 \text { studies provided data on sleep } \\
\text { disorders }(n=85,788) \text {. Meta-analysis showed that Food insecurity is associated with an } \\
\text { increased risk of testing positive for depression". }{ }^{4}\end{array}$ \\
\hline $\begin{array}{l}\text { Jafree } \\
\text { et al., } \\
2020\end{array}$ & 442 & $\begin{array}{l}\text { Cross- } \\
\text { sectional } \\
\text { study }\end{array}$ & Rural area & $\begin{array}{l}\text { "The chronic diseases faced by women include: high blood pressure }(85.5 \%) \text {, arthritis } \\
(81.3 \%) \text {, migraine }(56.0 \%) \text {, diabetes }(47.6 \%) \text {, and heart disease }(27.7 \%) \text {. The majority } \\
\text { of the sample was between the ages of } 18 \text { and } 39 \text {, with } 87.6 \% \text { happily married, } 94.0 \% \\
\text { illiterate, and } 70 \% \text { living below poverty lines. } 99.4 \% \text { of the people in the study have } \\
\text { one or two children, and the majority of them }(58.4 \%) \text { have experienced depression". } 13\end{array}$ \\
\hline $\begin{array}{l}\text { Rani et } \\
\text { al., } \\
2018\end{array}$ & 418 & $\begin{array}{l}\text { Community } \\
\text {-based } \\
\text { cross- } \\
\text { sectional } \\
\text { study }\end{array}$ & $\begin{array}{l}\text { Poverty and } \\
\text { urban slums }\end{array}$ & $\begin{array}{l}\text { "Almost half of households } 47.6 \% \text { were food insecurity among } 418 \text { girls; almost two- } \\
\text { fifths of households } 37.6 \% \text { were moderately uncertain, and } 4.5 \% \text { were seriously food } \\
\text { insecurity. High levels of anxiety } 64 \% \text {, depression } 57.7 \% \text {, psychiatric disorder } 58.4 \% \\
\text { and a low level of lack of behavioral control } 57.2 \% " .15\end{array}$ \\
\hline \begin{tabular}{l|} 
Shankar \\
et al., \\
2017
\end{tabular} & 23 & $\begin{array}{l}\text { Cross- } \\
\text { sectional } \\
\text { study }\end{array}$ & Food insecurity & $\begin{array}{l}\text { "Toddlers who lived with a temporary food deprived parent had minor but immediate } \\
\text { developmental consequences. Toddlers living with food deprived parents scored } 1.5 \\
\text { points lower on cognitive tests at } 24 \text { months". } 16\end{array}$ \\
\hline \begin{tabular}{|l|}
$\begin{array}{l}\text { Pourmo } \\
\text {-tabbed } \\
\text { et al., } \\
2019\end{array}$ \\
\end{tabular} & 372,143 & $\begin{array}{l}\text { Cross- } \\
\text { sectional } \\
\text { study }\end{array}$ & Food insecurity & $\begin{array}{l}\text { "The findings of this research revealed a favorable association between food insecurity } \\
\text { and the likelihood of depression and stress, not anxiety. Subgroup research by age } \\
\text { found that subjects older than } 65 \text { years of age had a greater risk of depression than } \\
\text { younger people, as well as a higher risk of depression in males than females". }{ }^{17}\end{array}$ \\
\hline \begin{tabular}{l|} 
Browne \\
et al., \\
2020
\end{tabular} & 15 & \begin{tabular}{l|} 
Questionnaire \\
-based \\
Cross- \\
sectional \\
study
\end{tabular} & $\begin{array}{l}\text { primarily } \\
\text { schizoph-renia } \\
\text { spectrum } \\
\text { disorders, bipolar } \\
\text { disorder, major } \\
\text { depressive disorder }\end{array}$ & $\begin{array}{l}\text { "Providers recorded having a good understanding of FI right after training }(\mathrm{M}=4.93 \text {, } \\
\mathrm{SD}=0.26, \mathrm{n}=15) . \text { In terms of evaluation, providers said they asked their clients about } \\
\text { their food access a moderate amount }(\mathrm{M}=3.50, \mathrm{SD}=1.08, \mathrm{n}=10) \text { but didn't use a } \\
\text { formal scale }(\mathrm{M}=1.30, \mathrm{SD}=0.95, \mathrm{n}=10) " .18\end{array}$ \\
\hline $\begin{array}{l}\text { Anjum } \\
\text { et al., } \\
2016\end{array}$ & 120 & \begin{tabular}{|l|} 
Descriptive \\
study
\end{tabular} & $\begin{array}{l}\text { Socio-economic } \\
\text { status, Poverty }\end{array}$ & $\begin{array}{l}\text { "Significant and clear correlation between the socio-economic position of the } \\
\text { respondents and the effect of food poverty on physiological defects and the irregular } \\
\text { health of children. A total of } 93.3 \% \text { of respondents were malnourished due to food } \\
\text { insecurity which influenced by normal weight growth. } 92.5 \% \text { felt that food poverty } \\
\text { influenced children's health". }{ }^{9}\end{array}$ \\
\hline $\begin{array}{l}\text { Lorey } \\
\text { et al., } \\
2019\end{array}$ & 11,906 & $\begin{array}{l}\text { Cross- } \\
\text { sectional } \\
\text { study }\end{array}$ & $\begin{array}{l}\text { House-hold Food } \\
\text { insecurity }\end{array}$ & $\begin{array}{l}\text { "Tubaramure(a food-assisted integrated health and nutrition program) significantly (P } \\
<0.05 \text { ) improved the percentage of food secure households, increased household } \\
\text { energy consumption (from } 17 \% \text { to } 20 \% \text { ) and micronutrient consumption. The program } \\
\text { had a positive effect on maternal dietary diversity and increased the proportion of } \\
\text { children aged 6-24yrs consuming food from } \geq 4 \text { food groups. The effects on many } \\
\text { outcomes were attributable to the food rations. Post-program effects were found on } \\
\text { household food security, maternal dietary diversity, and younger siblings' } \\
\text { complementary feeding practices". }{ }^{20}\end{array}$ \\
\hline \begin{tabular}{l|} 
Darling \\
et al., \\
2019
\end{tabular} & 98 & $\begin{array}{l}\text { Longitudinal } \\
\text { study }\end{array}$ & Food insecurity & $\begin{array}{l}\text { On the EDE-Q total score, "individuals with a background of food insecurity were } \\
\text { observed to have substantially higher levels of disordered eating patterns than } \\
\text { individuals with no history of food insecurity. Individuals with a history of food } \\
\text { insecurity reported significantly higher rates of depressive symptoms than individuals } \\
\text { with no history of food insecurity as measured by the Depression subscale of the } \\
\text { DASS". }\end{array}$ \\
\hline \begin{tabular}{l|} 
Maroto \\
et \\
al, 2015
\end{tabular} & 301 & \begin{tabular}{|l} 
Cross \\
sectional
\end{tabular} & Food Insecurity & $\begin{array}{l}\text { According to the findings, } 56 \text { percent of the students in the overall study were food } \\
\text { insecure. "Students who reported living alone or becoming single parents were at a } \\
\text { higher risk of food insecurity and were identified as African American or multiracial } \\
\text { were also more likely to be food insecure. Food insecure students were more likely to } \\
\text { register a lower GPA }(2.0-2.49) \text { versus a higher GPA }(3.5-4.0) \text { than food secure } \\
\text { students". } 22\end{array}$ \\
\hline $\begin{array}{l}\text { Tesfaye } \\
\text { et } \\
\text { al, } 2016\end{array}$ & 348 & $\begin{array}{l}\text { cross } \\
\text { sectional } \\
\text { study }\end{array}$ & Food insecurity & $\begin{array}{l}\text { "The prevalence of extreme household food insecurity was found to be } 38.7 \% \text { among } \\
\text { PLHIV. After correcting for confounders, higher levels of CMD symptoms }(=-1.72 \\
\text { for each } 1 \text { point rise, } 95 \text { percent CI: }-1.94 ;-1.49) \text { and extreme food insecurity (= }-3.24 \text {, } \\
95 \text { percent CI: }-6.19 ;-0.29) \text { were related to lower quality of life". }{ }^{23}\end{array}$ \\
\hline
\end{tabular}




\section{CONCLUSION}

This systematic review shows a strong linkage between food insecurity and depression, anxiety and stress. Our findings show an increase in the burden of common problems in mental health in people with poor socio-economic status. This relationship is obvious both in developing countries and in developed countries. On the basis of the results of this study, the tests of depression and mental health in both secured and food-insecure food areas should be mandatory at primary health level. More information relating to the effect of food insecurity on mental health must be examined in future studies. At last it is suggested that food insecurity interventions on national and regional levels may help reduce the prevalence of depression, anxiety, and stress and improve the overall mental health status of the community.

\section{REFERENCES}

1. Anderson SA. Core indicators of nutritional state for difficult-to-sample populations. The Journal of nutrition. 1990; 120(suppl_11):1555-1600.

2. Shen X, Gao X, Tang W, Mao X, Huang J, Cai, W. Food insecurity and malnutrition in Chinese elementary school students. British Journal of Nutrition. 2015; 114(6): 952-958.

3. Reksten AM, Somasundaram T, Kjellevold M, Nordhagen A, Bøkevoll A, Pincus LM, Aakre I. Nutrient composition of 19 fish species from Sri Lanka and potential contribution to food and nutrition security. Journal of Food Composition and Analysis. 2020; 91: 103508.

4. Hawkins M, Panzera A. Food insecurity: A key determinant of health. Archives of Psychiatric Nursing. 2020

5. Rani D, Singh JK, Acharya D, Paudel R, Lee K, Singh SP. Household food insecurity and mental health among teenage girls living in urban slums in Varanasi, India: a cross-sectional study. International journal of environmental research and public health. 2018; 15(8):1585.

6. Ishaq A, Khalid M, Ahmad E. Food Insecurity in Pakistan: A Region-Wise Analysis of Trends. Pakistan Institute of Development Economics (PIDE). 2018:157.

7. Husain W. Prevalent tendencies for mental disorders in Pakistan. Clinical and Health. 2018; 29(1):34-38.

8. Aslam N, Kamal A. Stress, anxiety, depression, and posttraumatic stress disorder among the general population affected by floods in Pakistan. Pakistan Journal of Medical Research. 2015; 55(1):29.

9. Chilton M, Black MM, Berkowitz C, Casey PH, Cook J, Cutts D, Meyers A. Food insecurity and risk of poor health among US-born children of immigrants. American journal of public health. 2009; 99(3): 556-562.

10. Shonkoff JP. From neurons to neighborhoods: old and new challenges for developmental and behavioral pediatrics. Journal of Developmental \& Behavioral Pediatrics.2003; 24(1):70-76.

11. WHO Organization. Depression and Other Common Mental Disorders: Global Health Estimates. Geneva: World Health Organization. 2017

12. Reincke K, Vilvert E, Fasse A, Graef F, Sieber S, Lana MA. Key factors influencing food security of smallholder farmers in Tanzania and the role of cassava as a strategic crop. Food Security. 2018; 10(4): 911-924.

13. Jafree SR. Determinants of depression in women with chronic disease: Evidence from a sample of poor loan takers from Pakistan. Journal of Community Psychology. 2020; 48(7): 2238-2251.

14. Arenas DJ, Thomas A, Wang J, DeLisser HM. A systematic review and meta-analysis of depression, anxiety, and sleep disorders in US adults with food insecurity. Journal of general internal medicine. 2019; 34(12): 2874-2882.

15. Rani D, Singh JK, Acharya D, Paudel R, Lee K, Singh SP. Household food insecurity and mental health among teenage girls living in urban slums in Varanasi, India: a cross-sectional study. International journal of environmental research and public health. 2018; 15(8): 1585.

16. Shankar P, Chung R, Frank DA. Association of food insecurity with children's behavioral, emotional, and academic outcomes: a systematic review. Journal of Developmental \& Behavioral Pediatrics. 2017; 38(2): 135-150.

17. Pourmotabbed A, Moradi S, Babaei A, Ghavami A, Mohammadi H, Jalili C, Miraghajani M. Food insecurity and mental health: a systematic review and meta-analysis. Public health nutrition. 2020: 23(10): 1778-1790.

18. Browne J, Ponce A. Assessing Food Insecurity in Individuals with Serious Mental Illness: A Pilot Training for Community Mental Health Providers. Community mental health journal. 2020: 56(6): 1110-1114.

19. Anjum F., Asim M, Awan KA, Saghir A, Nawaz Y. Household food insecurity and its impact on children's health in. Rawal Medical Journal. 2016; 41(3).

20. Leroy JL, Olney K, Bliznashka L, Ruel M. Tubaramure, a food-assisted maternal and child health, nutrition program in Burundi, increased household food security and energy and micronutrient consumption, and maternal and child dietary diversity: a cluster-randomized controlled trial. The Journal of nutrition. 2020;150(4): 945-957.

21. Darling KE, Fahrenkamp AJ., Wilson, SM, D'Auria AL, Sato AF. Physical and mental health outcomes associated with prior food insecurity among young adults. Journal of health psychology. 2020: 22(5): 572-581. 
22. Maroto ME, Snelling A, Linck H. Food insecurity among community college students: Prevalence and association with grade point average. Community College Journal of Research and Practice. 2015; 39(6): 515-526.

23. Tesfaye M, Kaestel P, Olsen MF, Girma T, Yilma D, Abdissa A, Hanlon C. Food insecurity, mental health and quality of life among people living with HIV commencing antiretroviral treatment in Ethiopia: a cross-sectional study. Health and quality of life outcomes. 2016; 14(1): 1-8.

24. Wolfe WS, Frongillo EA, Valois P. Understanding the experience of food insecurity by elders suggests ways to improve its measurement. The Journal of nutrition. 2003; 133(9): 2762-2769.

25. Alaimo K, Olson CM, Frongillo EA Jr. Food insufficiency and American school-aged children's cognitive, academic, and psychosocial development. Pediatrics. 2001; 108:44-53.

26. Cook JT. Impacts of child food insecurity and hunger on health and development in children: Implications of measurement approach. In Paper commissioned for the Workshop on Research Gaps and Opportunities on the Causes and Consequences of Child Hunger. 2013.

27. Weaver LJ, Hadley C. Moving beyond hunger and nutrition: a systematic review of the evidence linking food insecurity and mental health in developing countries. Ecology of food and nutrition. 2009; 48(4): 263-284.

28. Pruessner JC, Dedovic K, Pruessner M, Lord C, Buss C, Collins L, Dagher A, Lupien SJ. Stress regulation in the central nervous system: Evidence from structural and functional neuroimaging studies in human populations - 2008 Curt Richter Award Winner. Psychoneuroendocrinology.2010;35:179-91

29. Leonard BE. The HPA and immune axes in stress: The involvement of the serotonergic system. Eur. Psychiatry. 2005: 20 (Suppl. 3); S302-S306.

30. Lai KSP, Liu CS, Rau A, Lanctot KL, Kohler CA, Pakosh M, Carvalho AF. Herrmann, N. Peripheral inflammatory markers in Alzheimer's disease: A systematic review and meta-analysis of 175 studies. Journal of Neurology, Neurosurgery and Psychiatry 2017.

31. Pilgrim A, Barker M, Jackson A, Ntani G, Crozier S, Inskip H, Godfrey K, Cooper C, Robinson S. Does living in a food insecure household impact on the diets and body composition of young children? Findings from the Southampton Women's Survey. Journal of Epidemiology and Community Health. 2012: 66, e6.

32. Fenech M. Vitamins Associated with Brain Aging, Mild Cognitive Impairment, and Alzheimer Disease: Biomarkers, Epidemiological and Experimental Evidence, Plausible Mechanisms, and Knowledge Gaps. Advance in Nutrition. 2017; 8: 958-970.

33. Wattick RA, Hagedorn RL, Olfert MD. Relationship between diet and mental health in a young adult
Appalachian college population. Nutrients. 2018; 10(8):957.

34. Friel S, Berry H, Dinh H, O'Brien L, Walls HL. The impact of drought on the association between food security and mental health in a nationally representative Australian sample. BMC Public Health. 2014; 14(1):1102.

\section{The Authors}

Hamna Zahid

Final Year Student,

University Institute of Diet and Nutritional

Sciences,

The University of Lahore, Lahore.

Sana Noreen

Senior Lecturer,

University Institute of Diet and Nutritional

Sciences,

The University of Lahore, Lahore.

Bahisht Rizwan

Assistant Professor,

University Institute of Diet and Nutritional

Sciences,

The University of Lahore, Lahore.

Shahid Bashir

Associate Professor,

University Institute of Food Science and

Technology,

The University of Lahore, Pakistan

Shahwar Javaid

Final Year Student,

University Institute of Diet and Nutritional

Sciences,

The University of Lahore, Lahore.

Mujeeb Ur Rehman

Final Year Student,

University Institute of Diet and Nutritional

Sciences,

The University of Lahore, Lahore.

Dua Waqar

Final Year Student,

University Institute of Diet and Nutritional

Sciences,

The University of Lahore, Lahore.

Ayza Hashmi

Final Year Student,

University Institute of Diet and Nutritional

Sciences,

The University of Lahore, Lahore. 
Mahnoor Khalid

Final Year Student,

University Institute of Diet and Nutritional

Sciences,

The University of Lahore, Lahore.

Kinza Kashif

Final Year Student,

University Institute of Diet and Nutritional

Sciences,

The University of Lahore, Lahore.
Osama Rasheed

Final Year Student,

University Institute of Diet and Nutritional

Sciences,

The University of Lahore, Lahore.

\section{Corresponding Author:}

Sana Noreen

Senior Lecturer

University Institute of Diet and Nutritional

Sciences,

The University of Lahore, Lahore.

E-mail: sananoreen.rizwan@gmail.com 